\title{
Spectrum of dengue morbidity in pregnancy and its impact on maternal and perinatal outcome
}

\author{
Anuradha G., Sandya M. R.*, Shirley George
}

Department of Obstetrics and Gynecology, St. John’s Medical College Hospital, Bangalore, Karnataka, India

Received: 15 February 2019

Accepted: 07 March 2019

\section{*Correspondence:}

Dr. Sandya M. R.,

E-mail: drsamskruthii@gmail.com

Copyright: (C) the author(s), publisher and licensee Medip Academy. This is an open-access article distributed under the terms of the Creative Commons Attribution Non-Commercial License, which permits unrestricted non-commercial use, distribution, and reproduction in any medium, provided the original work is properly cited.

\begin{abstract}
Background: Dengue is a vector borne viral infection with seasonal outbreaks every year. The spectrum varies from just a febrile morbidity to the severe form of dengue shock syndrome (DSS). The objective of the present study was to study the influence of dengue fever on pregnancy and to analyze the maternal and perinatal outcome.

Methods: Thirty-six pregnant women beyond 28 weeks of gestation who tested positive for dengue infection were retrospectively analyzed during a 5year study period (Jan 2014-Dec 2018). The study was conducted in the Department of OBGYN St John's Medical College Hospital, Bangalore. Thirty-three of these patients delivered at St John's and there were three postpartum referral cases. The necessary data was obtained by patient record review. The data was analyzed using SPSS and the results were expressed as Mean \pm SD and percentages.

Results: Out of 36 women analyzed the mean age was found to be $23.93 \pm 4.5$ years. Majority were primigravidae $(58.3 \%)$. The most common clinical manifestation was fever seen in $47.2 \%$. Twenty five percent of patients had platelet count of $<20,000$ on admission. Overall $66 \%$ of the patients required transfusion. Nearly fifty three percent of the patients had vaginal delivery. There were 4 maternal mortalities $(11.1 \%)$ and 2 perinatal mortalities $(5.5 \%)$ both were still births in the present study.

Conclusions: Dengue infection in pregnancy was associated with increased maternal and perinatal morbidity as well as mortality. The severity of the infection has direct impact on the outcome. Hence early diagnosis and prompt management in a tertiary care centre, with multidisciplinary approach improves the outcome and minimizes the complications.
\end{abstract}

Keywords: Dengue, Maternal outcome, Pregnancy, Perinatal outcome, Thrombocytopenia

\section{INTRODUCTION}

Dengue fever is a mosquito borne febrile illness. The causative agent is dengue virus belonging to flaviviridae family, it is transmitted through Aedes aegypti mosquito. The dengue virus has four serotypes mainly (DENV-1, DENV-2, DENV-3, and DENV-4). The clinical severity of dengue infection has a wide spectrum and varies from simple uncomplicated fever to the most devastating Dengue Shock Syndrome (DSS). Dengue infection occurs as a seasonal outbreak. Infection by one serotype produces lifelong immunity to that specific serotype but only a few months of cross immunity against other serotypes. $^{1,2}$ The World Health Organization (WHO) previously classified dengue into three disease categories: Dengue Fever (DF), Dengue Hemorrhagic Fever (DHF) and Dengue Shock Syndrome (DSS). ${ }^{3}$ Due to several shortcomings in the above classification mainly the underestimation of the disease severity in some patients. $^{4,5}$ The WHO revised the dengue classification in the year 2009. ${ }^{6}$ As per the revised WHO classification the dengue cases are now classified as either dengue with or 
without warning signs or severe dengue. Dengue without warning signs is defined as an acute febrile illness with at least two of the following: nausea/vomiting, rash, aches and pains, leukopenia, and a positive tourniquet test. Dengue with warning signs is defined as abdominal pain, persistent vomiting, fluid accumulation, mucosal bleeding, lethargy, liver enlargement, and increasing hematocrit with reducing platelets, and at least one must be observed to fulfill the diagnosis of dengue with warning signs. Severe dengue is associated with severe plasma leakage, severe bleeding, or organ failure. ${ }^{6}$ Dengue infection in pregnant women carries the higher risk of haemorrhage for both the mother and the newborn. Maternal thrombocytopenia with platelet counts of less than 20,000 cells $/ \mathrm{mm}^{3}$ warrants platelet transfusion especially during labor or before planning cesarean section. There is increased risk of prematurity and perinatal mortality in patients with dengue infection in pregnancy. Few cases of vertical transmission causing neonatal thrombocytopenia have been reported in the literature requiring platelet transfusions. ${ }^{7,8}$ Elevated liver enzymes and thrombocytopenia could be confused with the diagnosis of Haemolysis, Elevated liver enzymes, Low platelet count (HELLP) syndrome which occurs in women with hypertensive disorders of pregnancy. The diagnosis of dengue infection affects the management options and decision making, particularly the mode of delivery due to potential risk of haemorrhage secondary to thrombocytopenia. Positive serology confirms the dengue infection and aids in differentiating it from other causes of thrombocytopenia. ${ }^{9}$ Authors undertook this study to analyse the influence of dengue fever on pregnancy and its impact on the maternal and perinatal outcome.

\section{METHODS}

Authors retrospectively analyzed 36 pregnant women beyond 28 weeks of gestation with positive dengue serology. The dengue infection was diagnosed by positive antigen (NS1) or antibody (IgG and IgM) on serology. The study was conducted in the Department of Obstetrics and Gynecology St John's Medical college over 5years (January 2014-December 2018). Pregnant women with positive dengue serology beyond 28 weeks of gestation were included in the study. Out of 36 women analyzed 33 of them delivered at our hospital and the other 3 were postpartum referral cases. Pregnant women with dengue infection prior to 28 weeks were excluded from the study. The data was obtained by patient record review. The data obtained was analyzed using SPSS Statistics version 22 software. Continuous variables are expressed as mean \pm standard deviation (SD) and nominal variables are expressed as percentages.

\section{RESULTS}

Thirty-six pregnant women seropositive for dengue infection were included. The mean age in the present study was $23.93 \pm 4.5$ years. Majority of the patients
$(58.3 \%)$ were primigravidae. Nineteen $(52.7 \%)$ were admitted at or beyond 37 weeks of gestation. Fever was the most common clinical manifestation seen in $47.2 \%$ of patients in the present study. NS1 antigen positivity was the most common serological parameter which led to the diagnosis of dengue infection in the present study seen in $14(38.8 \%)$ of patients (Table 1$)$.

Table 1: Patient profile and symptomatology $(n=36)$.

\begin{tabular}{|l|l|}
\hline Parameter & No. $(\%)$ \\
\hline Age (Years) & $23.93 \pm 4.5^{*}$ \\
\hline Parity & \\
\hline Primigravida & $21(58.3)$ \\
\hline Multigravida & $15(41.6)$ \\
\hline Gestational age at admission & \\
\hline $28-36^{+6}$ weeks & $14(38.8)$ \\
\hline$\geq 37$ weeks & $19(52.7)$ \\
\hline Postpartum & $3(8.3)$ \\
\hline Symptomatology & \\
\hline Fever & $17(47.2)$ \\
\hline Fever with myalgia & $7(19.4)$ \\
\hline Fever with hemorrhagic manifestation & $5(13.8)$ \\
\hline Fever with headache & $4(11.1)$ \\
\hline Fever with rash & $3(8.3)$ \\
\hline Dengue serology status & \\
\hline NS1 & $14(38.8)$ \\
\hline IgM & $6(6.6)$ \\
\hline NS1 + IgG & $5(13.8)$ \\
\hline NS1 + IgM & $4(11.1)$ \\
\hline IgG + IgM & $4(11.1)$ \\
\hline NS1 + IgG + IgM & $3(8.3)$ \\
\hline Expressed as Mean $\pm S D$ & \\
\hline
\end{tabular}

Fifteen $(41.6 \%)$ of patients had platelet count of 51,0001lakh cells/mm3 and $9(25 \%)$ of patients had severe thrombocytopenia with platelet count $<20,000$ cells $/ \mathrm{mm} 3$ at admission as shown in (Figure 1).

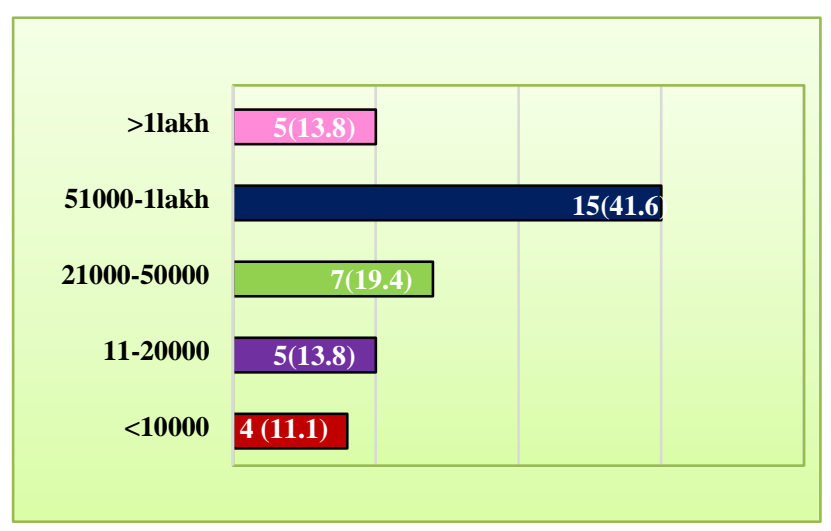

Figure 1: Platelet count at the time of admission expressed as cells $/ \mathrm{mm}^{3}(\mathrm{n}=36)$.

As shown in (Figure 2), $19(52.7 \%)$ of patients had vaginal delivery and $17(47.2 \%)$ had cesarean sections. Twenty-four $(66.7 \%)$ of patients required various blood 
component transfusion whereas $12(33.3 \%)$ did not require any transfusion during their course of treatment in the hospital (Figure 3).

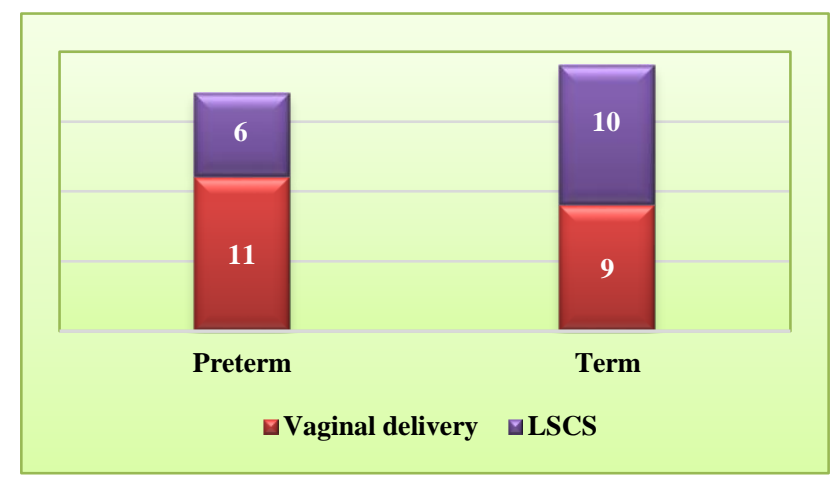

Figure 2: Mode of delivery $(n=36)$.

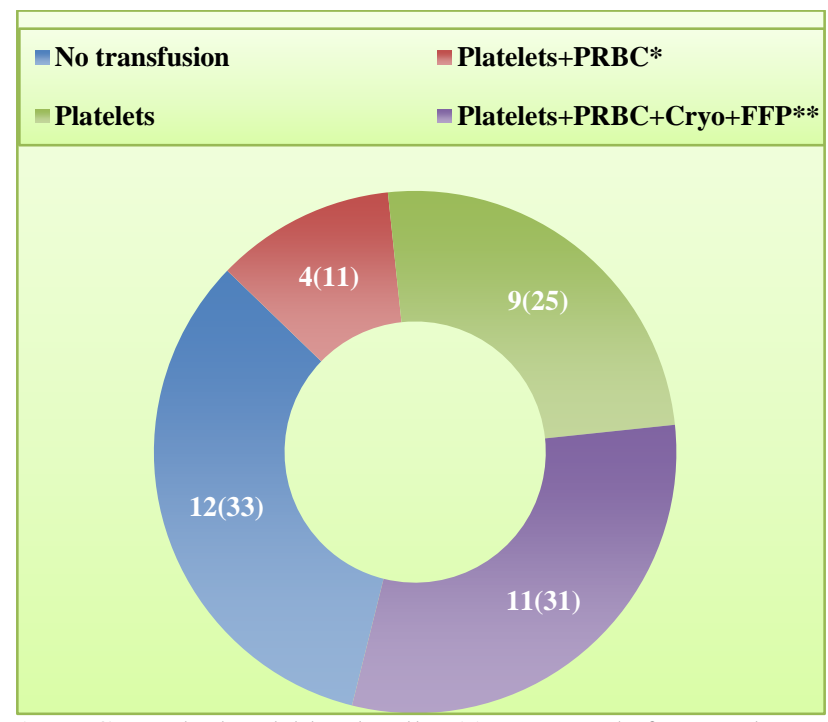

*PRBC- Packed red blood cells, ** FFP-Fresh frozen plasma Important to note $12(33 \%)$ of patients did not require any transfusion

Figure 3: Transfusion details $(n=36)$.

The obstetric complications related to placental insufficiency, with superadded hypertensive disorders of pregnancy and obstetric haemorrhage were seen in 8 $(22.2 \%), 10(27.7 \%)$ and $16(44.4 \%)$ of cases respectively (Table 2).

The other dengue associated maternal complications including $4(11.1 \%)$ maternal mortalities were as shown in (Table 3).

Among the 4 maternal mortalities 3 cases were referred in the postpartum period in a state of shock secondary to postpartum hemorrhage (PPH), following preterm vaginal delivery conducted outside.

Immediate resuscitative measures and massive blood and blood product transfusion was initiated in spite of which the patients could not be revived. The $4^{\text {th }}$ case was referred to us at 37 weeks of gestation with severe anemia (Hb-3g/dl), severe thrombocytopenia (Platelet count of 20,000 cell/ mm3) and fever of 102.F for the past 3 days. Following admission patient was still febrile with tachycardia (Temperature-102.F, Pulse rate-110 beats/min) and normal BP (110/70 $\mathrm{mmHg})$.

Table 2: Obstetric complications $(n=36)$.

\begin{tabular}{|l|l|}
\hline Complication & No**(\%) \\
\hline Placental insufficiency & $8(22.2)$ \\
\hline Oligohydramnios & 5 \\
\hline Fetal growth restriction (FGR) & 3 \\
\hline Hypertensive disorders of pregnancy & $10(27.7)$ \\
\hline Severe preeclampsia & 4 \\
\hline Eclampsia & 2 \\
\hline HELLP/AFLP & 4 \\
\hline Obstetric hemorrhage & $16(44.4)$ \\
\hline Antepartum hemorrhage (APH) & 2 \\
\hline Postpartum hemorrhage (PPH) & 14 \\
\hline *More than one complication was seen in the same patient \\
\hline
\end{tabular}

Table 3: Dengue associated maternal complications $(n=36)$.

\begin{tabular}{|l|l|}
\hline Complication & No. $(\%)$ \\
\hline ICU admission & $16(44.4)$ \\
\hline Dengue hepatitis & $11(30.5)$ \\
\hline Multi organ dysfunction (MODS) & $4(11.1)$ \\
\hline $\begin{array}{l}\text { Disseminated intravascular coagulation } \\
\text { (DIC) }\end{array}$ & $4(11.1)$ \\
\hline Dengue shock syndrome (DSS) & $4(11.1)$ \\
\hline Dengue polyserositis & $2(5.5)$ \\
\hline Adult respiratory distress syndrome (ARDS) & $2(5.5)$ \\
\hline Maternal mortality & $4(11.1)$ \\
\hline
\end{tabular}

*More than one complication was seen in the same patient 4 maternal mortalities include 3 - postpartum referral cases and 1 inpatient

She was managed with antipyretics, IV fluids, packed cells and platelets were transfused.

After stabilisation she was taken up for emergency cesarean section in view of non-reassuring NST (spontaneous decelerations up to 80 beats/min with beat to beat variability of $<5$ beats $/ \mathrm{min}$ ). Intraoperatively meconium stained amniotic fluid was noted, the baby cried after resuscitation and was shifted to NICU for further care.

The uterus was atonic and was managed with oxytocics and hemostatic sutures (B Lynch). She was shifted to ICU for monitoring, 2 hours following surgery she developed continuous oozing from the wound site, with intraabdominal bleeding.

She was given massive component therapy, in spite of all the resuscitative measures patient went into refractory hypotension, worsening metabolic acidosis, DIC and MODS hence could not be revived. 
Ultimately all the 4 patients succumbed to their illness severe dengue infection / (Dengue shock syndrome) with
DIC and MODS. The details of maternal mortality have been summarized in (Table 4).

Table 4: Details of maternal mortality $(n=4)$.

\begin{tabular}{|c|c|c|c|c|c|c|}
\hline $\begin{array}{l}\text { Age/ } \\
\text { Parity }\end{array}$ & $\begin{array}{l}\text { Period of } \\
\text { gestation } \\
\text { (weeks) }\end{array}$ & $\begin{array}{l}\text { Obstetric } \\
\text { outcome }\end{array}$ & Referred with & $\begin{array}{l}\text { Treatment } \\
\text { given }\end{array}$ & $\begin{array}{l}\text { Admission } \\
\text { to death } \\
\text { interval }\end{array}$ & Cause of death \\
\hline $\begin{array}{l}\text { 30/P1L0 } \\
\text { PND1 }\end{array}$ & 34 & $\begin{array}{l}\text { Preterm vaginal } \\
\text { delivery } \\
\text { Still born }\end{array}$ & \multirow{3}{*}{$\begin{array}{l}\text { Shock, Refractory } \\
\text { Hypotension, } \\
\text { Worsening } \\
\text { metabolic } \\
\text { acidosis }\end{array}$} & \multirow{3}{*}{$\begin{array}{l}\text { Intubation, } \\
\text { Platelets, FFP } \\
\text { transfusion }\end{array}$} & \multirow{3}{*}{$\begin{array}{l}\text { Less than } \\
2 \text { hours of } \\
\text { admission }\end{array}$} & \multirow{4}{*}{$\begin{array}{l}\text { Severe dengue } \\
\text { (Dengue shock } \\
\text { syndrome) with } \\
\text { DIC, MODS }\end{array}$} \\
\hline $\begin{array}{l}\text { 25/P1L1 } \\
\text { PND2 }\end{array}$ & 35 & $\begin{array}{l}\text { Preterm vaginal } \\
\text { delivery } \\
\text { Live born }\end{array}$ & & & & \\
\hline $\begin{array}{l}\text { 26/P1L0 } \\
\text { PND1 }\end{array}$ & 34 & $\begin{array}{l}\text { Preterm vaginal } \\
\text { delivery } \\
\text { Still born }\end{array}$ & & & & \\
\hline 22/Primi & 37 & $\begin{array}{l}\text { Emergency } \\
\text { Cesarean section } \\
\text { Live born }\end{array}$ & $\begin{array}{l}\text { Severe anemia, } \\
\text { thrombocytopenia, } \\
\text { epistaxis }\end{array}$ & $\begin{array}{l}\text { Packed cells, } \\
\text { Platelets, FFP } \\
\text { transfusion } \\
\text { Emergency } \\
\text { LSCS }\end{array}$ & 24 hours & \\
\hline
\end{tabular}

Among the perinatal complication's prematurity was the commonest complication which was seen in 17 (47.2\%) and there were 2 still births accounting to the perinatal mortality of $5.5 \%$ (Table 5).

Table 5: Perinatal complications $(n=36)$.

\begin{tabular}{|l|l|}
\hline Complication & No.*(\%) \\
\hline Preterm & $17(47.2)$ \\
\hline NICU care & $14(38.8)$ \\
\hline Fetal distress + meconium stained liquor & $12(33.3)$ \\
\hline Fetal growth restriction & $3(8.3)$ \\
\hline Perinatal mortality (Still birth) & $2(5.5)$ \\
\hline *More than one complication was seen in the same patient
\end{tabular}

Table 6: Neonatal complications $(n=36)$.

\begin{tabular}{|l|l|}
\hline Complication & No.*(\%) \\
\hline Fever & $5(13.8)$ \\
\hline Low birth weight/Small for gestational age & $4(11.1)$ \\
\hline Respiratory distress syndrome (RDS) & $4(11.1)$ \\
\hline $\begin{array}{l}\text { Neonatal thrombocytopenia } \\
\left(<1.5 \text { lakh cells/mm }{ }^{3}\right)\end{array}$ & $3(8.3)$ \\
\hline Neonatal sepsis & $3(8.3)$ \\
\hline Neonatal dengue (serology proven) & $2(5.5)$ \\
\hline Meconium aspiration syndrome (MAS) & $2(5.5)$ \\
\hline
\end{tabular}

Fever was the most common neonatal complication seen in 5 neonates. Neonatal thrombocytopenia (Platelet count of $<1.5$ lakh cells $/ \mathrm{mm}^{3}$ ) was seen in 3 neonates. There were 2 serological proven cases of neonatal dengue due to vertical transmission (Table 6). Both the babies diagnosed with neonatal dengue had good outcome

\section{DISCUSSION}

Thirty-six seropositive pregnant dengue patients as per the inclusion criteria were analyzed. The medical records of the patients were reviewed to obtain the necessary data. Authors hereby report our experience with dengue infection in pregnancy. Dengue should be an important differential diagnosis for any febrile morbidity in pregnancy, especially in endemic regions and more so during endemic outbreaks. In the previous published studies of dengue in pregnancy majority of women were in third trimester, in present study authors have only analyzed women in third trimester ( $>28$ weeks of gestation). ${ }^{11,12}$ Symptoms of dengue infection vary among the studies mentioned in the literature. The most common symptoms include fever, myalgia, arthralgia, this observation was similar to present study. Studies have reported that dengue is associated with higher rates of cesarean section, which was in contrast to our observation as authors had both vaginal deliveries and cesarean section more or less equally distributed in our patients. ${ }^{10,11,13-15}$ In the present study, the cesarean section was strictly done for obstetric indications and was not influenced by dengue. Thrombocytopenia was seen in most of the patients in present study cohort, similar to other published studies. ${ }^{11-13}$ Liver enzymes (AST, ALT) were elevated in majority of patients in the previous published studies, this observation was similar to present study wherein authors have described the condition as dengue hepatitis. ${ }^{10,11,16}$ Although hepatic involvement is 
not a primary target of dengue infection, it has been detected ranging from elevated transaminases to acute fulminant hepatitis to hepatic failure. ${ }^{16}$ Clinical or laboratory features of hepatic dysfunction could be used to triage patients and such patients might require intensive care admission and management. ${ }^{12}$ Similar to present study, case series done in srilanka also reported increased chances of HELLP syndrome and other complications of hypertensive disorders of pregnancy. ${ }^{12}$ Due to thrombocytopenia and elevated transaminases seen in both the conditions the differentiation might be difficult. Evidence of hemolysis and positive dengue serology aids in diagnosis. Secondary dengue infection is known to cause more severe disease sequel like severe dengue (DHF/DSS) infection as per latest WHO classification, this could be due to infection with a different serotype. Enhancement of cross-reactive cascade due to antibody dependent enhancement is believed to cause complement activation leading to endothelial dysfunction, platelet destruction and consumptive coagulopathy. ${ }^{2}$ The association between disease severity and secondary dengue was not analyzed in the present study. Observation in present study was similar to the study by Carlos et al, wherein they reported maternal mortality in 5 cases all had been diagnosed with severe dengue infection, this observation was similar to present study. ${ }^{17}$ Old studies report an association between low birth weight babies and dengue infection, with most of LBW attributed to prematurity. ${ }^{11-13}$ In present study, authors had $4(11.1 \%)$ LBW babies and there were 17 $(47.2 \%)$ premature babies which was more compared to the aforementioned studies. There were $2(5.5 \%)$ cases of neonatal dengue infection in the present study which was in agreement with a study by Basurko et al who also reported $5.6 \%$ rate of maternal-fetal transmission. Other neonatal consequences like low grade fever, rash, thrombocytopenia, low birth weight, prematurity have been reported in literature which were also analyzed in present study. ${ }^{13}$ A review article by Carles et al reported 5 in utero fetal deaths, in present study authors had 2 still births, both were out born babies and patients were referred to us only in the postpartum period. ${ }^{18}$ Study by Sharma et al reported 4 neonatal deaths $(25 \%)$ as contrast to present study. ${ }^{19}$ In summary, authors describe the maternal, perinatal and neonatal complications and outcomes of dengue infection during pregnancy. The present study is subject to limitations for its retrospective nature and also the important laboratory parameter (hematocrit) essential to monitor dengue patients was poorly documented and not analyzed in the present study.

\section{CONCLUSION}

Dengue fever in pregnancy increases the risk of hemorrhage to both the mother and the newborn. Early diagnosis and prompt treatment are required to minimize the complications. Dengue should always be considered in the differential diagnosis of febrile morbidity during pregnancy especially in endemic areas or recent travel to an endemic area. Diagnosis of dengue in pregnancy could be challenging due to atypical presentation and the presence of thrombocytopenia and elevated liver enzymes which could be confused with HELLP syndrome. Awareness programs on vector control and the management of dengue in pregnancy are essential to provide quality care. Authors also emphasize that not all patients with dengue infection complicating pregnancy will need blood transfusion. Dengue by itself is never an indication for obstetric interference in absence of fetomaternal complications.

\section{ACKNOWLEDGMENTS}

Authors would like to thank Dr. Sheela CN and Dr. Anamma Thomas for all the support.

Funding: No funding sources

Conflict of interest: None declared

Ethical approval: Not required

\section{REFERENCES}

1. Bharaj P, Chahar HS, Pandey A, Diddi K, Dar L, Guleria R, Kabra SK, Broor S. Concurrent infections by all four dengue virus serotypes during an outbreak of dengue in 2006 in Delhi, India. Virol J. 2008;5(1):1.

2. Gibbons RV, Vaughn DW. Dengue: an escalating problem. BMJ. 2002;324(7353):1563-6.

3. World Health Organization. Dengue haemorrhagic fever: diagnosis, treatment, prevention and control, 1997.

4. Balmaseda A, Hammond SN, Pérez MA, Cuadra R, Solano S, Rocha J, et al. Short report: Assessment of the World Health Organization scheme for classification of dengue severity in Nicaragua. Am J Trop Med Hyg 2005;73(6):1059-62.

5. Phuong CX, Nhan NT, Kneen R, Thuy PT, Van Thien C, et al. Clinical diagnosis and assessment of severity of confirmed dengue infections in Vietnamese children: is the World Health Organization classification system helpful? Am J Trop Med Hyg. 2004;70(2):172-9.

6. World Health Organization, Special Programme for Research, Training in Tropical Diseases, World Health Organization. Department of Control of Neglected Tropical Diseases, World Health Organization. Epidemic, Pandemic Alert. Dengue: guidelines for diagnosis, treatment, prevention and control. World Health Organization; 2009.

7. Carroll ID, Toovey S, Van Gompel A. Dengue fever and pregnancy - a review and comment. Travel Med Infect Dis. 2007;5(3):183-8.

8. Maroun SL, Marliere RC, Barcellus RC, Barbosa CN, Ramos JR, Moreira ME. Case report: vertical dengue infection. J De Pediatria. 2008;84(6):556-9.

9. Malhotra N, Chanana C, Kumar S. Dengue infection in pregnancy. Int J Gynaecol Obstet. 2006;94(2):1312. 
10. Malavige GN, Velathanthiri VG, Wijewickrama ES, Fernando S, Jayaratne SD, Aaskov J, Seneviratne SL. Patterns of disease among adults hospitalized with dengue infections. J Asso Physician. 2006;99(5):299-305.

11. Waduge R, Malavige GN, Pradeepan M, Wijeyaratne CN, Fernando S, Seneviratne SL. Dengue infections during pregnancy: a case series from Sri Lanka and review of the literature. $J$ Clinic Virol. 2006;37(1):27-33.

12. S. Kariyawasam and H. Senanayake. Dengue infections during pregnancy: case series from a tertiary care hospital in Sri Lanka. e J Infect Develop Countries 2010;4(11):767-75.

13. Basurko C, Carles G, Youssef M, Guindi WE. Maternal and foetal consequences of dengue fever during pregnancy. Europe J Obstet Gynecol Reproduct Biol. 2009;147(1):29-32.

14. Chitra TV, Panicker S. Maternal and fetal outcome of dengue fever in pregnancy. $\mathrm{J}$ Vector Borne Dis. 2011;48(4):210-4.

15. Malhotra N, Chinana C, Kumar S. Dengue infection in pregnancy. Int J Gynecol Obstet. 2006;94(2):1312.
16. Ooi ET, Ganesananthan S, Anil R, Kwok FY, Sinniah M. Gastrointestinal manifestations of dengue infection in adults. Med J Malaysia. 2008;63(5):4015.

17. Machain-Williams C, Raga E, Baak-Baak CM, Kiem S, Blitvich BJ, Ramos C. Maternal, Fetal, and Neonatal Outcomes in Pregnant Dengue Patients in Mexico. BioMed research international. 2018;2018.

18. Carles G, Talarmin A, Peneau CH, Bertsch M. Dengue fever and pregnancy. A study of 38 cases in French Guiana. J Gynecol, Obstet Reproduct Biol. 2000;29(8):758-62.

19. Sharma S, Jain S, Rajaram S. Spectrum of maternofetal outcomes during dengue infection in pregnancy: an insight. Infectious diseases in obstetrics and gynecology. 2016;2016.

Cite this article as: Anuradha G, Sandya MR, George S. Spectrum of dengue morbidity in pregnancy and its impact on maternal and perinatal outcome. Int J Reprod Contracept Obstet Gynecol 2019;8:1511-6. 